\title{
Heterogeneity of insulin responses: phases leading to Type 2 (non-insulin-dependent) diabetes mellitus in the rhesus monkey
}

\author{
B.C. Hansen and N.L. Bodkin \\ Department of Physiology, School of Medicine, University of Maryland at Baltimore, Baltimore, Maryland, USA
}

\begin{abstract}
Summary. To determine the natural history of the development of Type 2 (non-insulin-dependent) diabetes mellitus, basal plasma insulin and glucose levels and responses to intravenous glucose tolerance tests were determined over a period of 6 years in 42 adult male rhesus monkeys (Macaca mulatta). Among the 28 obese monkeys (percent body fat $>22 \%$ ) over the age of 10 years, 9 developed overt Type 2 diabetes (fasting plasma glucose, $>7.8 \mathrm{mmol} / 1$, and reduced glucose disappearance rates, $\mathrm{K}_{\mathrm{G}}<1.5$ ), and 14 monkeys have shown progressive changes which suggest that they may also become diabetic. Application of a highly constant antecedent diet and a consistent 16 -h fast minimized experimental variability, and permitted the identification of 8 phases in the progression from normal lean young adult to overt Type 2 diabetes. The earliest changes which could be detected were a slight in-
\end{abstract}

crease followed by a progressive rise in fasting plasma insulin levels and an increased insulin secretion in response to a glucose stimulus. These events preceded by several years the onset of a gradual deterioration of glucose tolerance. We found that hyper-, normo-, or hypoinsulinaemia could be associated with normoglycaemia or varying degrees of hyperglycaemia; however, the prospective longitudinal study of individual monkeys clearly identified this apparent heterogeneity of plasma insulin and glucose levels as reflecting sequential changes in a continuum of events preceding or accompanying the development of impaired glucose tolerance and Type 2 diabetes mellitus.

Key words: Rhesus monkeys, Macaca mulatta, obesity, glucose tolerance, hyperinsulinaemia, hyperglycaemia.
Type 2 diabetes mellitus has occasionally been reported to develop spontaneously in some adult rhesus monkeys [1-3]. These previous case reports provide evidence of similarities between the spontaneously occurring diabetes of non-human primates and Type 2 diabetes observed in humans. The adult-onset diabetes of rhesus monkeys (Macaca mulatta) is characterized by the classical clinical signs of polydipsia, polyuria, glycosuria, polyphagia, and, at advanced stages, loss of weight.

Observations of the progression of a few lean monkeys to an obese overtly diabetic state led us to hypothesize that some of the apparent heterogeneity in glucose and insulin responses seen in both humans and monkeys could be evidence of a continuum of events preceding the onset of diabetes. We therefore initiated this study of 42 adult male rhesus monkeys. Over a period of 6 years, 9 developed overt Type 2 diabetes, and 14 have shown transitions across various phases in the development of impaired glucose tolerance and the progression toward overt diabetes which suggest that they may also become diabetic. Substantive evidence is pre- sented to indicate that much, although not all, of the previously observed heterogeneity of Type 2 diabetes may represent a long series of phases in the time course of its development.

\section{Materials and methods}

\section{Animals}

Forty-two male rhesus monkeys (Macaca mulatta) have been studied over a period of 3 to 6 years. Subjects ranged in age from 3 to 28 years and weighed 5 to $31.7 \mathrm{~kg}$. All have been reared and maintained under laboratory conditions. They have always been housed in individual stainless steel primate cages under a 12-h light-dark cycle (lights on at 06.00 hours), with environmental temperature maintained at approximately $22^{\circ} \mathrm{C}$. At the initiation of this study 28 of the 42 monkeys were spontaneously obese, with percent body fat greater than $22 \%$, and all of those were over the age of 10 . The monkeys have been maintained in accordance with the National Institutes of Health Guide for the Care and Use of Laboratory Animals and all protocols have been reviewed and approved by the university animal care and use committee. 


\section{Diets}

The monkeys have been provided with ad libitum access to either monkey chow (Purina, St. Louis, Mo, USA, 15\% protein, 59\% carbohydrate, and $26 \%$ fat), or a complete liquid diet (Ensure, Ross Laboratories, Inc. Columbus, Ohio, USA, $14 \%$ protein, $54.5 \%$ carbohydrate and $31.5 \%$ fat). Both diets are equally adequate to maintain growth and health in rhesus monkeys.

\section{Procedures}

Fasting plasma glucose and insulin levels, and responses to an intravenous glucose load, were determined for all monkeys, generally at 6-month to 1-year intervals. All blood sampling and testing procedures were conducted following a consistent, strictly maintained 16 -h overnight fast with a constant antecedent diet in order to minimize interexperimental variability. Ketamine hydrochloride was used for anaesthesia (10 $\mathrm{mg} / \mathrm{kg}$ body wt.), since our own observations have confirmed the reports of Kemnitz and Kraemer [4] and of Brady and Koritnik [5] that ketamine has no effect on the results of an intravenous glucose tolerance test. A peripheral intravenous catheter was placed, and four blood samples 3 min apart were collected and pooled for measurement of fasting plasma insulin and glucose levels, a procedure necessitated by the known frequency of oscillations in basal plasma insulin levels in monkeys and in humans $[6,7]$.

Intravenous glucose tolerance tests (IVGTT) were conducted following collection of the fasting, baseline samples. A $50 \%$ glucose solution (13.9 mmol glucose per kg of body wt.) was infused intravenously over a 30-s period, and blood samples were then withdrawn at $1,3,5$, $10,15,20,30,45$, and $60 \mathrm{~min}$ after the termination of the glucose bolus. Heparinized saline was infused between samples to maintain the patency of the intravenous catheter. All blood samples were immediately transferred to chilled heparinized tubes, placed on ice, and then centrifuged at $20^{\circ} \mathrm{C}$. After separation of the plasma and erythrocytes, plasma samples were frozen for later assays. Percent body fat was determined by a tritiated water dilution method $[8,9]$.

\section{Assays}

Plasma glucose levels were measured using either the glucose oxidase method with a glucose autoanalyzer (Beckman Instruments, Fullerton, Calif, USA) or the hexokinase and glucose-6-phosphate dehydrogenase method of Slein [10]. Plasma insulin levels were measured by a modification [11] of the double antibody radioimmunoassay of Morgan and Lazarow [12] using anti-pork insulin serum, $I^{125}$ labeled pork insulin as the tracer and human insulin as the standard. Rhesus monkey insulin has been shown to be identical to human insulin [13].

\section{Statistical analysis}

The glucose disappearance rate $\left(\mathrm{K}_{\mathrm{G}}\right)$ was calculated using the time points between the 5 and 20 min plasma glucose values during the IVGTT, a time period which corresponded to the period of linear fall in plasma glucose levels in these monkeys.

The analysis of longitudinal data aimed at determining the time course of hormonal and metabolic changes presumed to be related to Type 2 diabetes mellitus was complicated by a number of factors. For example, the number, nature, and duration of the phases in the progression to diabetes were unknown as were the ideal time intervals between experiments. Also, among potentially useful variables, the relative weighting or importance of each variable, particularly at various phases in the development of diabetes, was not known. Further, the rate of progression of individual monkeys through one or a series of phases was likely to vary between monkeys. Finally, the initial point at which each monkey was first studied was a random event relative to degree of progression of the disease process. Therefore, the following approach was used to analyze these data.

First, a set of variables related to diabetes mellitus was identified for initial examination and analysis. These variables included age, body weight, fasting plasma glucose levels, fasting plasma insulin levels, and glucose disappearance rate $\left(\mathrm{K}_{\mathrm{G}}\right)$.

The first and second phases were then identified, and both included only monkeys with fully normal insulin levels and glucose tolerance responses. The first phase included all monkeys under the age of 10 years, and all were lean. The second phase included monkeys over the age of 10 years, both lean and obese, but otherwise normal. Because it was not known in advance how many phases might be identifiable or optimal, we defined further only the final phase as "overt diabetes" consistent with the criteria the National Diabetes Data Group [14] and the World Health Organization [15] for obesityassociated Type 2 diabetes. Phases between phase 2 and overt diabetes emerged from the data analysis as follows: Data sets composed of the previously noted variables were arrayed for each monkey in sequential order from the earliest to the most recent set of data. These data sets were then used to determine the optimal number of phases on the basis of maximal homogeneity within phases. One way analysis of variance (ANOVA) was subsequently used to identify the differences across the phases for individual variables, and the significance of specific differences was conservatively determined using Scheffe's contrast method (Student's t-test) [16]. Regression analysis was used to assess the continuum of sequential changes across phases for selected variables, and partial correlation analyses were used to estimate the relationship between two variables after controlling for the effect of a third variable.

\section{Results}

Two monkeys were overtly diabetic at the initiation of this study, and seven monkeys progressed to overt diabetes while under study. Fourteen additional monkeys have shown changes suggesting they are progressing toward diabetes. Five other obese monkeys have remained stable and shown no progression toward diabetes. The pattern of the progressive process is shown in Figure 1 for one monkey (Monkey W). This monkey was already hyperinsulinaemic, but normoglycaemic, at age 13 , and became diabetic by age 17 . Changes in fasting plasma glucose and insulin, and accompanying changes in body weight, are seen prior to and after the development of diabetes (designated Phase 8).

Data analysis which maximized homogeneity of glucose tolerance and insulin data within phases, while maintaining the chronological sequence of observations within monkeys, led to the identification of 8 phases in the progression from normal lean young adult to Type 2 diabetes. Observations falling into each phase were further analyzed in order to characterize the key features, which were found to differentiate a particular phase from its neighboring phases in this progressive process.

Phase 1 included the 12 adult monkeys who were between the ages of 3 and 8.9 years. All were lean (percent body fat 4 to $16 \%$ ) and ranged in weight from 5 to $9.1 \mathrm{~kg}$. All had normal fasting plasma glucose and insulin levels, and normal glucose disappearance rates as shown in Table 1.

Twelve additional monkeys, ages 11.4 to 27.7 years, were identified initially as in phase 2 . This phase included only observations from animals which, like those identified to be in phase 1 , were entirely normal in fasting plasma glucose and insulin levels, and had a 
normal $\mathrm{K}_{\mathrm{G}}$ in response to an IVGTT (Table 1). They were defined as phase 2 because they differed in age from phase 1 ( $>10$ years). Monkeys with observations in phase 2 fell into one of two subgroups: middle-aged lean $(8.4$ to $9.3 \mathrm{~kg}$ ) and middle-aged obese (11.1 to $15.9 \mathrm{~kg}$ ). Six of the 12 monkeys initially found to be in phase 2 have remained there. Thus, a total of 18 monkeys remained in either phase 1 or phase 2 and are currently normal by the measures included. (Only 3 other monkeys have shown no change of phase during our observations: two were already in the final phase (overt diabetes); the third has remained in one of the middle phases throughout the study.)

Table 1 provides a summary of the numbers of monkeys and the observations in each phase. All monkeys in phases 2 through 8 were over age 10. Age did not differ

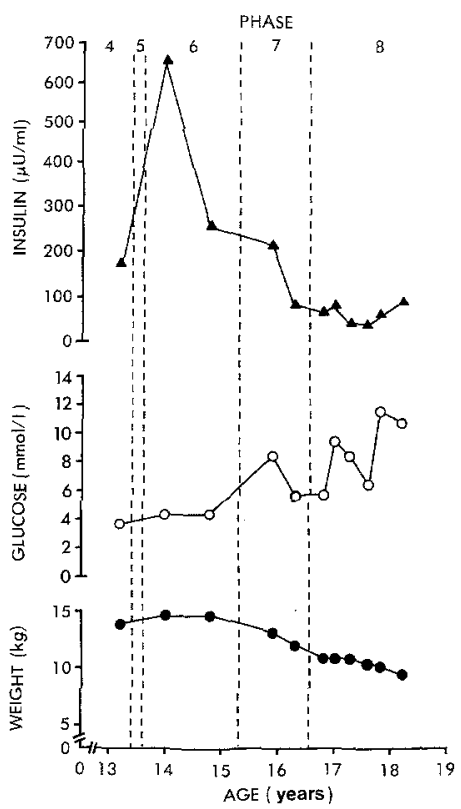

Fig. 1. Changes in fasting plasma insulin and glucose levels and body weights of Monkey W during the progression to phase 8 (overt Type 2 diabetes) substantially over phases (e.g., age range $9.6-20.5$ years for phases $3-5$, and 12.2 to 21.3 for phases $6-8)$. The age at which monkeys first reached phase 8 (overt Type 2 diabetes) ranged from 14.8 to 21.3 years. There was a slight negative relationship $(r=-0.28 ; p=0.08)$ between age and glucose tolerance across the progression in obese monkeys progressing toward diabetes (phases 2 through 8). Age, however, accounted for only $8 \%$ of the variance in $\mathrm{K}_{\mathrm{G}}$.

Mean body weight in phase 2 was more than 2SD above the mean of phase 1 . Body weight showed no change or only slight increases in phases 2 through 5 , followed by gradual declines in phases 6 through 8 both within individual monkeys (Figure 2) and within the group as a whole (Table 1). Significant weight loss occurred in phase 8 during a period of exacerbated glycosuria, prior to the initiation of insulin treatment. Percent body fat changed in parallel with changes in body weight $(r=0.82 ; p<0.001)$ as reported previously [17]. Correlational analysis of percent body fat and glucose tolerance showed no significant relationship, whether analyzed across the progression with age held constant $(r=-0.26 ; p=\mathrm{ns})$ or when comparing obese monkeys phases $2-6$ or phases $6-8(r=0.10, p=\mathrm{ns} ; r=0.10$, $p=\mathrm{ns}$ respectively). While all monkeys who showed the progressive development of Type 2 diabetes were obese, some obese monkeys have shown no progression toward diabetes, remain in phase 2 , and show fully normal glucose tolerance.

Details of the longitudinal nature of the progression of diabetes are evident in the data of seven individual monkeys shown by phase (Fig. 2), and phase designations have also been added to Figure 1 for monkey W, with data shown by age. The progressive rise and then fall in fasting plasma insulin, the very late rise in fasting plasma glucose, and the relatively late deterioration of $\mathrm{K}_{\mathrm{G}}$ are evident. This pattern is also evident in Table 1, which includes all data of all monkeys, whether or not they reached the overt diabetes phase.

Table 1. Characteristics of monkeys in the progression of impaired glucose tolerance and Type 2 diabetes ${ }^{\mathrm{a}}$

\begin{tabular}{|c|c|c|c|c|c|c|c|c|}
\hline Phases & 1 & 2 & 3 & 4 & 5 & 6 & 7 & 8 \\
\hline Monkeys (n) & 12 & 12 & 13 & 15 & 10 & 6 & 7 & 7 \\
\hline Age (years) & $\begin{array}{r}5.6 \pm 0.6^{\mathrm{h}} \\
(3.0-8.9)\end{array}$ & $\begin{array}{c}15.9 \pm 1.5 \\
(11.4-27.7)\end{array}$ & $\begin{array}{c}15.2 \pm 0.7 \\
(10.6-20.1)\end{array}$ & $\begin{array}{c}15.0 \pm 0.7 \\
(9.6-19.6)\end{array}$ & $\begin{array}{c}15.3 \pm 0.9 \\
(10.3-20.5)\end{array}$ & $\begin{array}{c}16.2 \pm 0.8 \\
(14.3-19.6)\end{array}$ & $\begin{array}{c}16.7 \pm 1.0 \\
(12.2-20.1)\end{array}$ & $\begin{array}{r}18.3 \pm 0.9^{c} \\
(14.8-21.3)\end{array}$ \\
\hline Body weight $(\mathbf{k g})$ & $\begin{array}{r}6.3 \pm 0.4^{b} \\
(5.0-9.1)\end{array}$ & $\begin{array}{r}13.2 \pm 0.5^{d} \\
(11.1-15.9)\end{array}$ & $\begin{array}{r}16.1 \pm 0.4 \\
(14.3-18.2)\end{array}$ & $\begin{array}{r}17.4 \pm 0.9^{\mathrm{b}} \\
(13.7-28.4)\end{array}$ & $\begin{array}{cc}18.6 & \pm \\
(13.6 & -31.7)\end{array}$ & $\begin{array}{c}17.5 \pm 1.1 \\
(14.5-22.2)\end{array}$ & $\begin{array}{r}16.2 \pm 1.0 \\
(12.5=19.6)\end{array}$ & $\left\{\begin{array}{r}14.7 \pm 0.7^{c} \\
(11.9-16.9)\end{array}\right.$ \\
\hline Body fat $(\%)$ & $\begin{array}{l}9.7 \pm 2^{b} \\
(4 \quad-16)\end{array}$ & $\mid \begin{array}{c}25.5 \pm 2^{d} \\
(22-29)\end{array}$ & $\begin{array}{l}32.2 \pm 2 \\
(25-38)\end{array}$ & $\begin{array}{ccc}34.7 & \pm & 2 \\
(24 & -49)\end{array}$ & $\begin{aligned} 35 & \pm 3 \\
(31 & -44)\end{aligned}$ & $\begin{array}{c}34.9 \pm \quad 2 \\
(25 \quad-44)\end{array}$ & e & $\begin{array}{c}25.7 \pm 3 \\
(18-30)\end{array}$ \\
\hline $\begin{array}{l}\text { Fasting plasma } \\
\text { glucose } \\
(\mathrm{mmol} / \mathrm{l})\end{array}$ & $\begin{array}{c}3.7 \pm 0.1 \\
(3.2-4.2)\end{array}$ & $\begin{array}{c}3.8 \pm 0.1 \\
(3.2-4.2)\end{array}$ & $\begin{array}{c}3.7 \pm 0.1 \\
(3.3-4.2)\end{array}$ & $\begin{array}{c}3.8 \pm 0.1 \\
(3.3-4.2)\end{array}$ & $\begin{array}{c}3.8 \pm 0.1 \\
(3.4-4.4)\end{array}$ & $\begin{array}{c}4.4 \pm 0.2 \\
(3.7-4.9)\end{array}$ & $\begin{array}{r}6.3 \pm 0.6^{b} \\
(4.3-9.2)\end{array}$ & $\begin{array}{l}10.8 \pm 1.1^{6} \\
(8.0-16.2)\end{array}$ \\
\hline $\begin{array}{l}\text { Fasting plasma } \\
\text { insulin }(\mu \mathrm{U} / \mathrm{ml})\end{array}$ & $\begin{array}{cl}42 & \pm 3.0 \\
(23 & -54)\end{array}$ & $\begin{array}{cl}50 & \pm 4.2 \\
(23 & -72)\end{array}$ & $\begin{array}{ll}101 & \pm 5.6 \\
(70 & -128)\end{array}$ & $\begin{cases}161 & \pm 7.2^{6} \\
127 & -247)\end{cases}$ & $\begin{aligned} 311 & \pm 25.6^{b} \\
(207 & -443)\end{aligned}$ & $\begin{cases}415 & \pm 84.2^{b} \\
(195 & -777)\end{cases}$ & $\begin{cases}99 & \pm 12.6 \\
(57 & -155)\end{cases}$ & $\begin{array}{ll}45 & \pm 5.1 \\
(27 & -63)\end{array}$ \\
\hline $\begin{array}{l}\text { Glucose } \\
\text { disappearance } \\
\text { rate }\left(\mathrm{K}_{\mathrm{G}}\right)\end{array}$ & $\begin{array}{c}3.6 \pm 0.2 \\
(4.40-2.90)\end{array}$ & $\left\{\begin{array}{c}3.5 \pm 0.2 \\
(4.16-2.69)\end{array}\right.$ & $\begin{array}{cl}3.6 \pm & 0.2 \\
(3.92- & 3.27)\end{array}$ & $\begin{array}{cl}2.7 \pm & 0.1 \\
(3.42- & 1.82)\end{array}$ & $\begin{array}{cl}2.5 \pm & 0.2^{\mathrm{b}} \\
(3.27- & 1.28)\end{array}$ & $\begin{array}{c}2.3 \pm 0.2^{b} \\
(2.79-1.76)\end{array}$ & $\begin{array}{c}1.6 \pm 0.1^{\mathrm{b}} \\
(2.07-1.24)\end{array}$ & $\begin{array}{c}1.1 \pm 0.1^{b} \\
(1.47-0.78)\end{array}$ \\
\hline
\end{tabular}

"Mean \pm SE. ${ }^{b}$ Significantly different from Phase 2 by ANOVA; $p<0.05$. ' Denotes age and weight at onset of Phase 8. Current ages (because of cases of long-standing diabetes) range from 19.5 to 22.8 years. ${ }^{\mathrm{d}}$ Includes obese normal subjects only. Phase 2 lean subgroup: $8.78 \pm 0.5 \mathrm{~kg} ; 14.0 \pm 1 \%$ body fat. "Data not available 


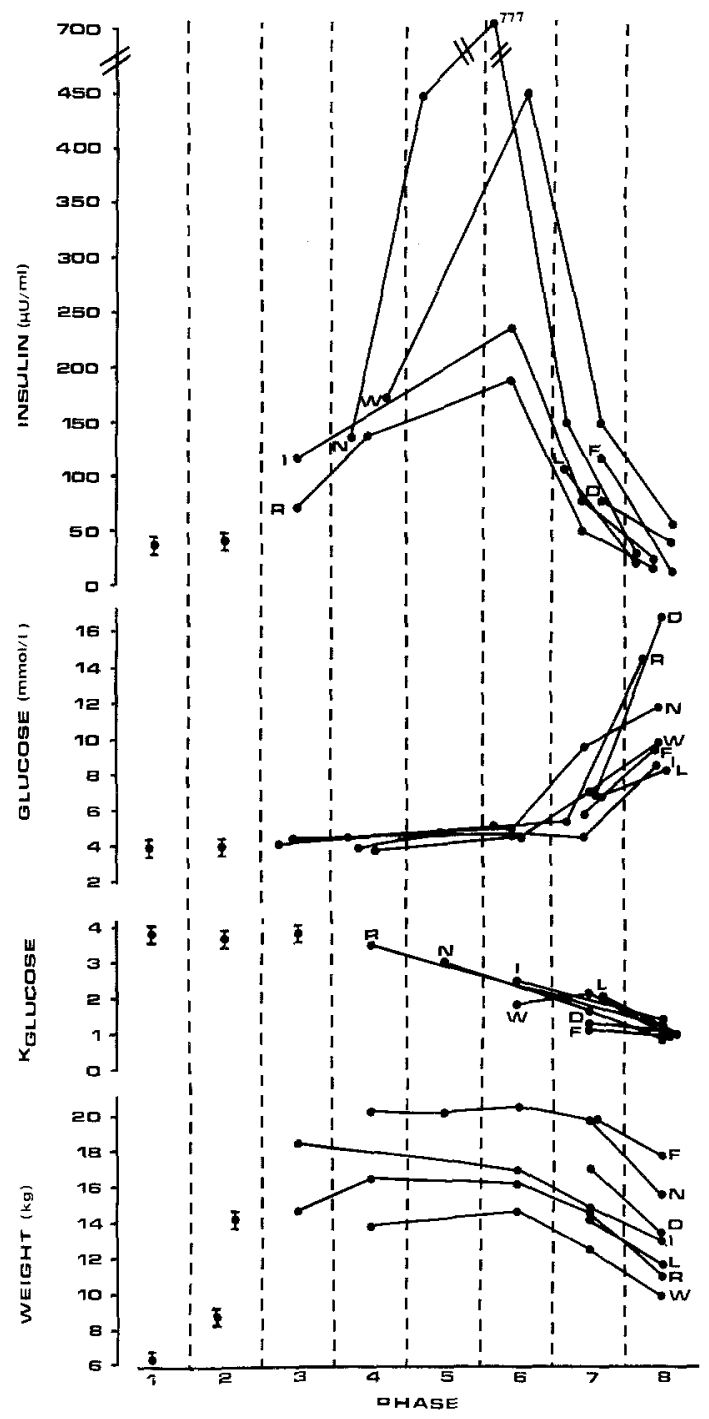

Fig. 2. Fasting plasma insulin and glucose levels, glucose disappearance rate $\left(\mathrm{K}_{\mathrm{G}}\right)$ in response to an intravenous glucose tolerance test, and body weight changes in subjects who became overtly diabetic (monkeys D, F, I, L, N, R, and W). Group data on young lean (phase 1) and older lean and obese monkeys (phase 2) (mean $\pm \mathrm{SE}$ ) are shown for reference

To summarize, the key variables which were found to differentiate the phases were as follows: Phases 1 and 2 were defined a priori as less than or more than 10 years of age.

Phase 3 included those observations showing the first detectable increase in fasting plasma insulin above those of phase 2 , yet preceding the statistically significant increase in fasting plasma insulin found in phase 4 $(p<0.05)$. Phase 3 could not be distinguished statistically from phase 2 or 4 . However, because monkeys were followed across time, we were able retrospectively, based on each monkey's individual transitions, to identify the point at which there was a detectable increase.

The principal determinant of phase 4 was a significant increase in fasting insulin of greater than 2 SD above the mean for phase $2(p<0.05)$. All insulin levels in phase 4 were greater than the highest insulin level ob- served in phase 2. Fasting plasma glucose remained within normal range.

Phase 5 was characterized as showing the further development of hyperinsulinaemia (minimum fasting plasma insulin $>2$ SD above mean of phase 3 ). While the mean $\mathrm{K}_{\mathrm{G}}$ in phase 5 was statistically significantly decreased compared to phases 1 and $2(p<0.05)$, there remained some overlap in the ranges of $\mathrm{K}_{\mathrm{G}}$ across phases 1-5. Fasting plasma glucose levels remained normal.

Further exacerbation of the hyperinsulinaemia was apparent in phase 6 (2SD above the mean for phase 4 ). Phase 6 also showed the earliest change in fasting plasma glucose (detectable only by history in animals progressing from phases 5 to 6 to 7). Most of the monkeys $(83 \%)$ in phase 6 had fasting plasma glucose levels more than $1 \mathrm{SD}$ above the mean of phase 2; however, some showed entirely normal plasma glucose levels in phase 6.

All $\mathrm{K}_{\mathrm{G}}$ values in phase 7 were significantly decreased (2 SD below the mean of phase 2), and, for the first time, in phase 7 there was no overlap in range of $\mathrm{K}_{\mathrm{G}}$ with those of phases 1 or 2 . Fasting plasma insulin levels were highly variable $(29 \%$ had returned to within normal range: phase 2 mean $\pm 2 \mathrm{SD}$, while the remainder had insulin levels as high as $155 \mu \mathrm{U} / \mathrm{ml}$ ); however, all monkeys showed a decrease between phases 6 and 7 . All fasting plasma glucose levels in phase 7 were at least $1 \mathrm{SD}$ above phase 2 normal levels, and the group mean plasma glucose for phase 7 was significantly higher than phase $2(p<0.05)$.

Phase 8 showed a statistically significant rise in fasting plasma glucose $(p<0.05)$, with all values $>2 \mathrm{SD}$ above the mean of phase 2 . Furthermore, $\mathrm{K}_{\mathrm{G}}$ was significantly and progressively decreased with all values less than $2 \mathrm{SD}$ below the mean $\mathrm{K}_{\mathrm{G}}$ for phase 4 . Fasting plasma insulin levels were within the normal range, showing no difference from either phase 1 or 2 , but were more than $2 \mathrm{SD}$ below the levels of phase 6 . All subjects showed decreases in fasting plasma insulin in the transition from phase 7 to phase 8 . Regression analysis of fasting plasma insulin levels in the subjects who were followed longitudinally from phases 3 to 6 showed a highly significant linear increase $(r=0.74 ; p<0.02)$ similar to that observed in the 42 subjects followed crosssectionally $(r=0.83 ; p<0.001)$. Fasting plasma insulin levels and $\mathrm{K}_{G}$ were inversely correlated in phases 2 to 6 $(r=-0.58 ; p=0.003)$ and positively correlated in phases 6 to 8 ( $r=0.76 ; p=0.002)$.

The progressive changes in responses to an intravenous glucose tolerance test are summarized in Figures $3 \mathrm{a}$ and $3 \mathrm{~b}$. Because of the progressive rise and then fall of insulin response across phases, these data were best shown by plotting phases 1 through 4 and phases 5 through 8 in separate figures (Figs. $3 \mathrm{a}$, b), with phase 1 repeated in Figure $3 b$ for reference only.

In summary, 21 monkeys passed through 2 or more sequential phases leading toward the development of 

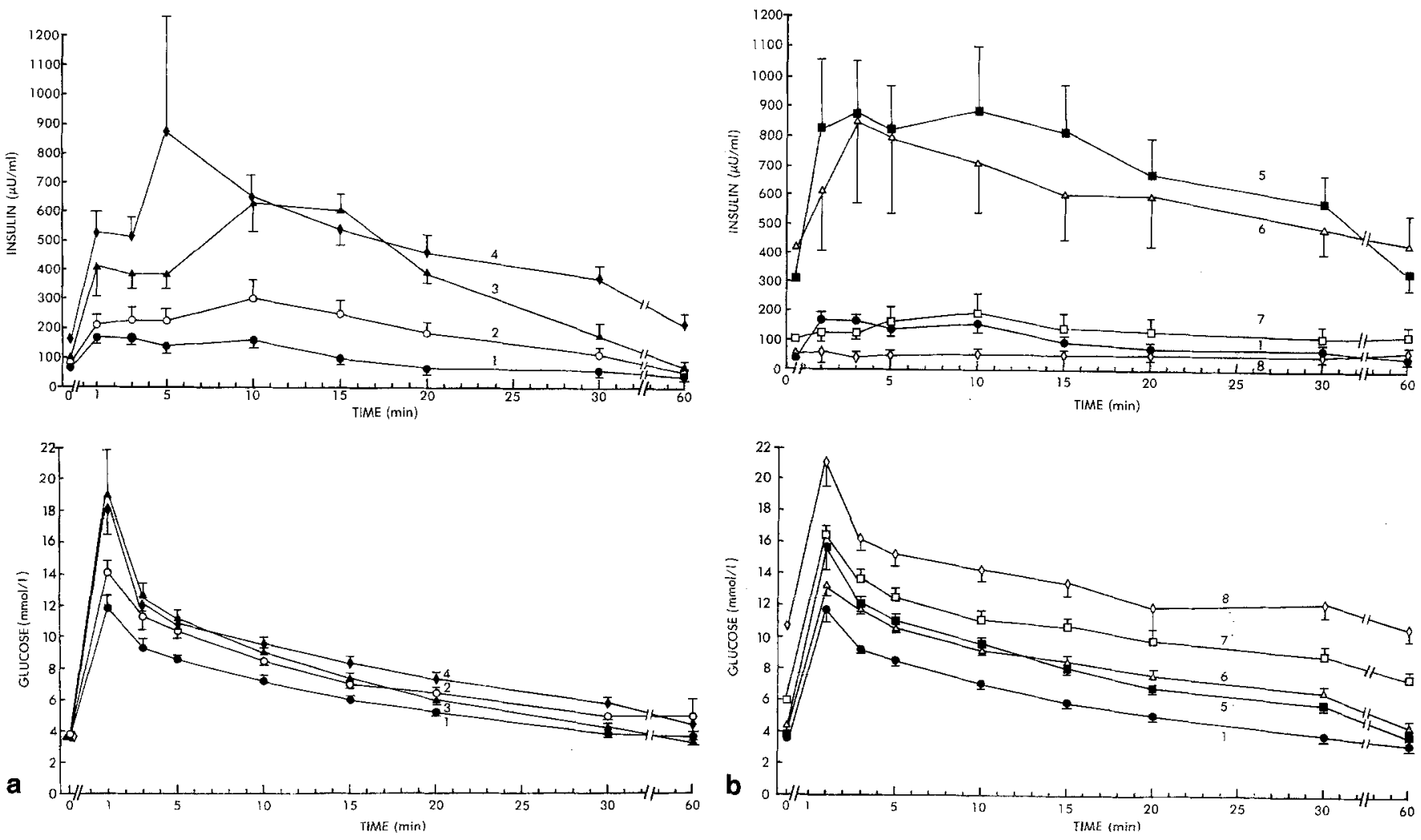

Fig. $3 \mathbf{a}$ and b. Plasma insulin and glucose response to intravenous glucose tolerance tests with observations grouped by phase. Phases 1 ( $\bullet$ ), $2(0), 3(\Delta)$, and $4(\diamond)$ are shown in and phases $5(\mathbf{\Delta}), 6(\Delta), 7(\square)$, and $8(\diamond)$ [plus phase $1(\bullet)$ for reference] are in b

diabetes, and seven of those monkeys have made the transition to overt Type 2 diabetes during this study. Analyses of these transitions have led to the characterization of the changes in plasma glucose and insulin levels and glucose tolerance preceding overt Type 2 diabetes.

\section{Discussion}

The spontaneous Type 2 diabetes mellitus which develops in some obese rhesus monkeys has previously been shown to be similar in clinical manifestations to Type 2 diabetes in humans [1, 18]. The high incidence of Type 2 diabetes in spontaneously obese monkeys has made possible our observations of its relatively rapid development and progression. Specifically, the prospective and cross-sectional study of 42 monkeys, 7 of which developed overt Type 2 diabetes, and 14 of which have shown transitions which suggest they are likely to become diabetic, has clarified the sequence of events in the natural history of the disease, and has led to the tentative identification of eight phases in this adult-onset obesityassociated disease process.

No rhesus monkeys have been observed in our laboratory to show hyperglycaemia, glycosuria, impaired glucose tolerance, or overt Type 2 diabetes prior to approximately age 14 (middle age) or at body weights (at diabetes onset) of less than $10 \mathrm{~kg}$ under free feeding conditions.

Concerning the role of obesity per se, or degree of obesity, in the progression of Type 2 diabetes, we conclude that obesity in the monkey appears to be a necessary but not a sufficient condition to the progressive development of adult-onset diabetes. While all monkeys were obese prior to the onset of Type 2 diabetes, change in fat mass, as observed previously in humans [19], had little or no effect on the progression toward overt Type 2 diabetes. Some obese monkeys have not shown signs of developing diabetes, despite similar degrees of obesity, duration of obesity, and ages to those who have become overtly diabetic. Similarly, Reaven et al. [20] and others $[21,22]$ have been unable to document a significant relationship between degree of obesity and insulin action in humans. Whether weight reduction in obese monkeys prior to the onset of significant hyperinsulinaemia or prior to the onset of glucose intolerance can prevent the progression to diabetes must await further study.

Neither diet nor environmental conditions differentiated those monkeys that became diabetic from those that did not, since all animals had been maintained under the same conditions. The role of genetics in the development of diabetes could not be determined, since these monkeys were unrelated and were not used for breeding.

In the progression from normal to the overt diabetic state, the earliest change which we have to date been 
able to detect was a slight and then progressive increase in fasting plasma insulin level. This observation preceded any change in the fasting plasma glucose level or in the rate of glucose disappearance during an IVGTT. In previous studies in humans [20, 23], "normal" subjects have generally been defined on the basis of normal glucose tolerance. Therefore, it is likely that so-called normal or control subjects, particularly obese normal subjects, may have had widely varying plasma insulin levels (e.g., might have included individuals ranging from phases 1 through 6), and thus might not have been truly normal (i.e., phases 1 or 2). Thus, hyperglycaemia and altered glucose tolerance cannot be used to indicate the onset of the processes leading to Type 2 diabetes, although they may be useful for epidemiological studies and for clinical treatment and prognostic purposes.

These data from monkeys are congruent with what have heretofore been viewed as a highly diverse set of observations made in human subjects and often referred to as the "heterogeneity" of diabetes. For example, the bimodality of fasting glucose observed in a population study of Pima Indians [24] is precisely what would be anticipated if this group shows the same progressive process in the development of Type 2 diabetes as we have observed in monkeys. That is, the transitional phases (e.g., phases 6-7) are relatively rapid compared to the preceding period of normoglycaemia, and the final phase of diabetes which, once reached, lasts indefinitely. Thus, a bimodal cross-sectional sample distribution for fasting plasma glucose would be expected. Other studies [25-27] have reported among humans a wide range of plasma insulin responses to glucose in subjects of different degrees of glucose tolerance, as we have shown in monkeys. Our data are also in agreement with the previous report that day-long circulating insulin levels are within normal limits in severely hyperglycaemic patients [28], since we commonly observed normoinsulinaemia in the advanced phase of diabetes in our monkeys.

Further evidence of the variability in insulin levels as related to glucose tolerance was seen in our data in monkeys in the earlier phases of the progression showing an increased plasma insulin response as glucose tolerance deteriorated (phases 2 through 6 ) followed by a marked decline in $\mathrm{K}_{\mathrm{G}}$ concommitant with a decreased insulin secretion in the later phases of the progression (phases 6 through 8).

Reaven and Olefsky [25] also reported patients with impaired glucose tolerance who had increased, normal, or lower insulin responses to glucose. We suggest that this variability may be equivalent to our phases 6 and 7 , where the transition from high to low plasma insulin levels does not appear to be directly related to the changes in glucose tolerance; that is, the drop in plasma insulin levels preceded, was coincident with, or followed the most significant deterioration of glucose tolerance.
Weir [29] has posited that the small number of diabetic subjects who had high insulin responses to an oral glucose challenge will eventually be recognized as having a separate disorder. The present data from monkeys suggest that those human subjects may eventually show a decline in insulin response, and may be shown to have been in a transitional period (phase 7 in our designation) along the continuum progressing to marked hyperglycaemia and diabetes.

The similarities between our observations in monkeys and previous reports in humans are further evident in studies of patients during the period immediately preceding the development of overt diabetes. For example, the 40 patients $(11.7 \%)$ of Kosaka et al. [30], who initially had fasting blood sugars of less than $7.8 \mathrm{mmol} / \mathrm{l}$, low insulin responses, and varying degrees of glucose tolerance, appear similar to some of our subjects in phase 7. In other studies, e.g. Keen et al. [31] in a 10-year follow-up, Kadowaki et al. [32] in a 5 to 12-year follow-up, and Sasaki et al. [33] in a 7-year follow-up, $15 \%, 25 \%$ and $38.5 \%$ (respectively) of subjects with "borderline" diabetes progressed to overt Type 2 diabetes. Therefore, although some report that only a portion of patients with impaired glucose tolerance progress to diabetes [34], this observation may be related to the probable varying rate of progression and, for some individuals, a very prolonged transition, rather than a true separation of impaired glucose tolerance from diabetes. The time course for such progression, a process which appears to take 3 to 6 years in rhesus monkeys, may take 10 to 30 years or more in humans.

In summary, these observations in monkeys suggest that the etiologic or pathogenic mechanisms of Type 2 diabetes must be sought in proximity to the earliest detectable abnormality. It seems unlikely that the primary defect underlying the development of Type 2 diabetes is an absolute deficiency of insulin, although such a deficiency may be the proximate cause of the late deterioration in glucose tolerance and the necessity to implement treatment. An early enhanced basal secretion of insulin could be evidence of the onset of the primary event, possibly a B cell or B-cell control abnormality. Alternatively, these observations may be evidence of an underlying progressive development of insulin resistance or reduced sensitivity to the action of insulin in peripheral tissues with relative cellular glucopenia or of a subtle and undetectable increased glycaemia stimulating an enhanced B-cell output. Clearly, individuals must be studied prospectively from the point of not only normal glucose tolerance, but also normoinsulinaemia and normal B-cell response, in order to identify the primary defect in the onset and progression of Type 2 diabetes, and potentially to enhance efforts directed toward early treatment and prevention.

Acknowledgments. The authors are indebted to their scientific collaborators, Drs. S.B.Pek, K.-L.C.Jen, and B.L.Metzger, and the many fellows, research assistants and students who have been involved with these studies over the years including especially 
D. M. Harman, C. S. Sweeley, T. A. Russell, G.P. Schielke, S. Gray, and L. M.Speegle. We thank M. Hendricks, J. Vaughn, and S. Strange for their assistance in the preparation of this manuscript and J. Richardson and $\mathrm{H}$. Ortmeyer for illustration services. This study was supported in part by National Institutes of Health grants DK37717, AM20572 (Diabetes Research and Training Center, University of Michigan), and AM20579 (Diabetes Center, Washington University), Southern Illinois University, and the Northwest Medical Research Foundation.

\section{References}

1. DiGiacomo RF, Myers RE, Baez LR (1971) Diabetes mellitus in a rhesus monkey (Macaca mulatta): a case report and literature review. Lab Anim Sci 21: 572-574

2. Kirk JH, Casey HW, Harwell JF (1972) Diabetes mellitus in two rhesus monkeys. Lab Anim Sci 22: 245-248

3. Hamilton CL, Ciaccia P (1978) The course of development of glucose intolerance in the monkey (Macaca mulatta). J Med Primatol $7: 165-173$

4. Kemnitz JW, Kraemer GW (1982) Assessment of glucoregulation in rhesus monkeys sedated with ketamine. Am J Primatol 3: $201-210$

5. Brady AG, Koritnik DR (1985) The effects of ketamine anesthesia on glucose clearance in African green monkeys. J Med Primatol 14: $99-107$

6. Hansen BC, Pek S, Koerker DJ, Goodner CJ, Wolfe RA, Schielke GP (1981) Neural influences on oscillations in basal plasma levels of insulin in monkeys. Am J Physiol 240 (Endocrinol Metab 3): E5-E11

7. Hansen BC, Jen K-LC, Pek SB, Wolfe RA (1982) Rapid oscillations in plasma insulin, glucagon, and glucose in obese and normal weight humans. J Clin Endocrinol Metab 54: 785-792

8. Moore FD (1946) Determination of total body water and solids with isotopes. Science 104: 157-160

9. Pace N, Kline L, Schachman HK, Harfenist M (1947) Studies on body composition. IV. Use of radioactive hydrogen for measurement in vivo of total body water. J Biol Chem 168: 459-469

10. Slein MW (1971) D-glucose determination with hexokinase and glucose-6-phosphate dehydrogenase. In: Bergmeyer HV (ed) Methods of enzymatic analysis. Academic, New York, pp 117-123

11. Hayashi M, Floyd JC Jr, Pek S, Fajans SS (1977) Insulin, proinsulin, glucagon and gastrin in pancreatic tumors in the plasma of patients with organic hyperinsulinism. $J$ Clin Endocrinol Metab 44: 681-694

12. Morgan CR, Lazarow A (1963) Immunoassay of insulin. Two antibody system - plasma insulin levels of normal, subdiabetic and diabetic rats. Diabetes 12: 115-126

13. Naithani VK, Steffens GJ, Tager HS, Buse G, Rubenstein AH, Steiner DF (1984) Isolation and amino-acid sequence determination of monkey insulin and proinsulin. Hoppe-Seyler's Z Physiol Chem 365: 571-575

14. National Diabetes Data Group (1979) Classification and diagnosis of diabetes mellitus and other categories of glucose intolerance. Diabetes 28: 1039-1057

15. WHO Technical Report Series, No 646. (1980) Who Chronicle 34: 361

16. Scheffe H (1959) The analysis of variance. Wiley, New York

17. Jen K-LC, Hansen BC, Metzger BL (1985) Adiposity, anthropometric measures, and plasma insulin levels of rhesus monkeys. International J Obesity $9: 213-224$

18. Metzger BL, Hansen BC, Speegle LM, Jen K-LC (1985) Characterization of glucose intolerance in obese monkeys. J Obes Wt Reg 4: $153-167$

19. Vague J, Vague Ph, Tramoni M, Vialettes B (1983) Clinical features of diabetogenic and atherogenic obesity. Tohoku J Exp Med 141 (Suppl): 145-159

20. Reaven GM, Moore J, Greenfield M (1983) Quantification of insulin secretion and in vivo insulin action in nonobese and moderately obese individuals with normal glucose tolerance. Diabetes 32: 600-604

21. Bogardus C, Lillioja S, Mott D, Reaven GR, Kashiwagi A, Foley JE (1984) Relationship between obesity and maximal insulin-stimulated glucose uptake in vivo and in vitro in Pima Indians. J Clin Invest 73: 800-805

22. Bogardus C, Lillioja S, Mott DM, Hollenbeck C, Reaven G (1985) Relationship between degree of obesity and insulin action in man. Am J of Physiol 248 (Endocrinol Metab 11) E286-291

23. Bogardus C, Lillioja S, Howard BV, Reaven G, Mott D (1984) Relationships between insulin secretion, insulin action and fasting plasma glucose concentration in nondiabetic and noninsulin-dependent diabetic subjects. $\mathrm{J}$ Clin Invest 74: 1238-1246

24. Bennett PH, Knowler WC, Pettitt DJ, Carraher MJ, Vasquez B (1982) Longitudinal studies of the development of diabetes in the Pima Indians. In: Eschwege E (ed) Advances in diabetes epidemiology. Elsevier, Amsterdam Oxford New York, pp 65-74

25. Reaven GM, Olefsky JM (1977) Relationship between heterogeneity of insulin responses and insulin resistance in normal subjects and patients with chemical diabetes. Diabetologia 13: 201-206

26. Savage PJ, Dippe SE, Bennett PH, Gordon P, Roth J, Rushforth NB, Miller M (1975) Hyperinsulinemia and hypoinsulinemia - insulin responses to oral carbohydrate over a wide spectrum of glucose tolerance. Diabetes 24: 362-368

27. Zimmett P, Whitehouse S, Alford F, Chisholm D (1978) The relationship of insulin response to a glucose stimulus over a wide range of glucose tolerance. Diabetologia 15:23-27

28. Liu G, Coulston A, Chen Y-DI, Reaven GM (1983) Does day-long absolute hypoinsulinemia characterize the patient with non-insulin-dependent diabetes mellitus? Metabolism 32: 754-756

29. Weir GC (1982) Noninsulin-dependent diabetes mellitus: interplay between B-cell inadequacy and insulin resistance. Am $\mathbf{J}$ Med 73: $461-464$

30. Kosaka K, Hagura R, Kuzuya T (1977) Insulin response in equivocal and definite diabetes, with special reference to subjects who had mild glucose intolerance but later developed definite diabetes. Diabetes 26: 944-952

31. Keen H, Jarrett RJ, McCartney P (1982) The ten-year follow-up of the Bedford Survey (1962-1972): glucose tolerance and diabetes. Diabetologia 22: 73-78

32. Kadowaki T, Miyake Y, Hagura R, Kajinuma H, Kuzuya N, Akanuma Y, Kosaka K (1983) On the pathogenesis of Type II diabetes with special reference to diminished insulin response and obesity: a 5-12 year follow-up study of subjects with borderline glucose tolerance. Tohoku J Exp Med 141 (Suppl): 141-146

33. Sasaki A, Suzuki T, Horiuchi N (1982) Development of diabetes in Japanese subjects with impaired glucose tolerance: a seven year follow-up study. Diabetologia 22: 154-157

34. Reaven GM (1984) Insulin secretion and insulin action in noninsulin-dependent diabetes mellitus: which defect is primary? Diabetes Care 7 (Suppl 1): 17-24

Received: 19 February 1986

and in revised form: 1 August 1986

Dr. B.C. Hansen

Department of Physiology

c/o Graduate School, Suite 257

University of Maryland

660 West Redwood Street

Baltimore, MD 21201

USA 